\title{
O PAPEL DO DOCENTE NA UNIVERSIDADE
}

\author{
THE ROLE OF THE PROFESSOR AT THE UNIVERSITY
}

Vital Paulino Costa

Chefe do Setor de Glaucoma do Hospital das Clínicas da UNICAMP. Docente. Faculdade de Medicina da USP e da Faculdade de Ciências Médicas da UNICAMP.

CoRRESPONDÊNCIA: Rua Bauru, 40 - CEP 01248-010 São Paulo- SP. FAX -11-3865-9630 - email: vp.costa@uol.com.br

COSTA VP. O papel do docente na universidade. Medicina, Ribeirão Preto, 35: 505-508, out./dez. 2002.

RESUMO: A docência universitária é o produto final de um longo e custoso processo formativo, que somente se concretiza, quando o docente se apercebe da necessidade e exerce intensa atividade de multiplicador cultural. Tal atividade exige um grau de conscientização, nem sempre adquirido após uma profícua produção científica. Este artigo visa discutir um tripé, no centro do qual deve se posicionar o docente pertencente à Universidade: o ensino, a prestação de serviços à comunidade e a pesquisa. Enfatiza-se a inter-relação entre os três componentes, assim como a necessidade de uma dedicação harmoniosa do docente a cada elemento da tríade.

UNITERMOS: Universidade. Ensino, Pesquisa. Comunidade. Responsabilidade.

A docência universitária é o produto final de um longo e custoso processo formativo, que somente se concretiza, quando o docente se apercebe da necessidade e exerce intensa atividade de multiplicador cultural. Tal atividade exige um grau de conscientização, nem sempre adquirido após uma profícua produção científica. Não é raro ver cientistas recém-chegados do Exterior demonstrarem desprezo por suas universidades atrasadas, incapazes de lhes proporcionar recursos adequados para que prossigam na sua carreira de investigação. Nesse momento, é fundamental que o pesquisador se julgue corresponsável pela situação e que inicie uma luta árdua e incessante na busca de soluções. Não basta simplesmente aguardar que as autoridades universitárias desenvolvam os meios necessários para que a meta seja atingida. É fundamental que o jovem pesquisador atue com determinação, para criar as melhores condições para a evolução da Universidade.

Por outro lado, é freqüente o encontro de pesquisadores que valorizam apenas o caráter honorífico da docência, desejada como um título de qualificação e prestígio junto a clientelas profissionais, externas à Universidade. O docente precisa ter um papel ativo e de dedicação prioritária à Universidade, que deve, num "feedback" constante, estimulá-lo a permanecer voltado para os interesses da própria Universidade, mais que aos seus próprios. Trata-se de valorizar o chamado espírito universitário, que prioriza a tolerância e a convivência, apesar da diversidade de personalidades e idéias. Ao ser incorporado ao quadro de docentes de uma universidade, é importante que se tenha a noção exata da responsabilidade de tal cargo. Ao tomar uma posição, pronunciar-se, enfim, agir, o nome da Universidade passa a estar em jogo, tanto quanto o seu próprio.

Como propunha Darcy Ribeiro ${ }^{(1)}$, a Universidade deve respeitar três princípios básicos, a saber: a) o respeito aos padrões internacionais de cultivo e difusão do saber; b) o compromisso ativo com a busca de soluções para os problemas do desenvolvimento global e autônomo da sociedade nacional; c) a liber- 
dade de manifestação de pensamento por docentes e estudantes. São princípios que traduzem um tripé, no centro do qual deve posicionar-se o docente da Universidade: o ensino, a prestação de serviços à comunidade e a pesquisa. Na verdade, todos os vértices desse triângulo se intercomunicam, como se pode observar na discussão que se segue.

\section{ENSINO}

Quanto à atividade de ensino na Universidade, desde a graduação até a residência médica e a pósgraduação, um dos dilemas mais discutidos diz respeito à aparente contraposição entre a abordagem humanística e a visão pragmática do ensino. A dúvida traduz-se na oposição entre o Humanismo, definido como a atitude dos herdeiros do saber humano, e o Pragmatismo, empregado por aqueles que valorizam o lado prático do ensino, incluindo experiências científicas e tecnológicas. Trata-se, na realidade, de um pseudodilema, visto que não há Humanismo sem fundamentação científica ou Ciência que não germine a partir do conhecimento prévio.

Como, então, ensinar? Uma das grandes lições que aprendi ao longo da minha vida acadêmica é que há diferença entre a técnica de ensino de um cientista e a técnica de ensino de um professor de ginásio. $\mathrm{O}$ último transmite o conhecimento de forma estanque, formado por uma série de verdades inquestionáveis. $\mathrm{O}$ primeiro questiona todo e qualquer conhecimento previamente adquirido, incita a dúvida, estimula o processo de investigação. Neste momento, é claro, para mim, que o docente ideal dever ter uma abordagem que una a didática irreparável ao espírito questionador, que transmita o conhecimento com segurança, mas que esteja atento às dúvidas de seu aluno, por mais absurdas que pareçam.

Talvez uma subcontrovérsia da discussão anterior, mais específica para a carreira médica seja a oposição entre o cientificismo e o profissionalismo. Como decidir entre o cultivo à ciência e o incentivo ao treinamento com suas repercussões práticas? De modo similar à questão anterior, não há como optar por uma ou outra abordagem sem comprometer a formação do médico. A ciência possui valor prático insubstituível e o seu ensino enriquece a formação técnica de qualquer profissional, seja ele da área médica ou não. $\mathrm{O}$ técnico que aprende a questionar e que compreende a origem do conhecimento utilizado no seu dia-a-dia tem maior capacidade de executar suas funções e, even- tualmente, de torná-las mais eficazes. A Universidade deve preparar médicos de alta capacidade de trabalho e qualificação, da qual a sociedade necessita para viver e progredir. Entretanto, deve, ao mesmo tempo, estimular jovens que justifiquem um investimento adicional a prosseguir na carreira acadêmica e científica, criando um ciclo virtuoso.

Finalmente, o ensino médico se confunde com $\mathrm{o}$ atendimento à Comunidade. Ao mesmo tempo em que presta serviço à população que procura um hospital universitário ou um posto de saúde, cada paciente examinado, sempre sob a supervisão de uma equipe, é matéria prima, viva, bruta, formada por conhecimento a ser desvendado e ensinado, num processo que transcende o mero diagnóstico e tratamento.

\section{PRESTAÇÃO DE SERVIÇOS À COMUNI- DADE}

O docente deve estar bem situado diante da realidade que o cerca, estabelecendo um compromisso com a Universidade, a Nação e seus problemas de desenvolvimento, em detrimento da postura acadêmica mais tradicional, dedicada à erudição gratuita, sem vínculo social, sem uma atitude cidadã. Os hospitais universitários desempenham função social de destaque, não só pelo atendimento que prestam aos usuários do Sistema Único de Saúde, como, também, pelo auxílio à formação de profissionais da área médica, que se disseminarão pelo País e multiplicarão o efeito do ensino.

É neste sentido que se insere a importância de projetos específicos que atendam à Comunidade, o que pode ser obtido por dois caminhos. Inicialmente, podese dispor da Universidade para o desenvolvimento de projetos comunitários de efeito imediato, como os Projetos-Catarata, desenvolvidos por várias universidades brasileiras. Não fossem tais projetos, o acesso de milhares de pacientes aos hospitais, às cirurgias propriamente ditas, aos cuidados pós-operatórios e até à prescrição dos óculos seriam luxo de uma pequena parcela da população.

Outro papel da Universidade em relação à Comunidade diz respeito à educação e conscientização da mesma sobre os problemas de saúde que acometem a população, seu diagnóstico, tratamento e prevenção. Em outras palavras, a atividade de ensino do docente deve extrapolar a população médica, para atingir a população que o cerca. É inquestionável a importância dessa abordagem na percepção da saúde pela população. 
Paralelamente, o estímulo à pesquisa científica resulta, a médio ou longo prazos, em descobertas, potencialmente, de impacto social. A descoberta do tratamento da oncocercíase, o desenvolvimento do HAART ("Highly Activea Anti-Retroviral Therapy) no tratamento da SIDA, a pesquisa do genoma humano, só para citar alguns exemplos, justificam que o estímulo à atividade científica deva ser encarado como parte integrante da missão comunitária, tamanha sua repercussão social.

A preocupação do ensino não pode estar voltada para a doença de maneira isolada, mas para o indivíduo como um todo, inserido em uma comunidade. A Universidade não deve formar técnicos capazes de diagnosticar e tratar o paciente que está sendo examinado naquele instante. Deve formar médicos que se preocupam com a população e com o paciente de maneira global, respondendo perguntas como: Como aquele paciente chegou até o médico? Quais os obstáculos que teve que vencer? Quantos pacientes conseguem chegar aos consultórios e em que estágio da doença? Como possibilitar o acesso universal dos necessitados? Como facilitar a aderência ao tratamento? Como atender adequadamente um maior número de pacientes com menor custo?

\section{PESQUISA}

É função da Universidade dominar e transmitir o conhecimento científico, existente, ensinando a todos os estudantes as bases do método empírico-indutivo, os fundamentos da experiência científica e da observação. Como discutido nos parágrafos anteriores, a atividade científica é simultaneamente o propulsor da Universidade e o amálgama que mantém indissociável o tripé da atividade docente. A integração das atividades científicas e docentes será conseguida desde que o docente tenha em mente que toda investigação universitária deve ser explorada como fonte de ensino e treinamento e que nenhum investigador deve esquivar-se do exercício do ensino. O pesquisador que ensina leva para a sala de aula o inconformismo e a incerteza que conduzem o jovem a perceber, no conhecimento incompleto, a forma de lidar com o desconhecido e de questionar o que se supõe conhecido.

Entretanto, no estágio em que nos encontramos, não devemos nos preocupar exclusivamente em realizar pesquisas de ponta ou utilizar tecnologia avançada. Se assim for, continuaremos beneficiando, quem sabe, uma porcentagem mínima da população. Os esforços devem ser direcionados à formação de médicos com uma visão global e comunitária, capazes de aplicar tecnologia apropriada e desenvolver pesquisas com o propósito de aumentar a abrangência, possibilitar o diagnóstico mais precoce e preservar a capacidade visual do paciente. Em outras palavras, a produção científica das universidades brasileiras não reflete, necessariamente, as neceassidades do País. Na maioria das vezes, segue a tendência acadêmica mundial, o que facilita sua inclusão em grupos internacionais e a publicação de artigos em periódicos de circulação mundial.

Com o desenvolvimento das subespecialidades da Oftalmologia, há um progresso constante e vertiginoso no conhecimento da Fisiopatologia e tratamento das diversas moléstias oculares. Concomitantemente, houve uma perda do sentido de conjunto, resultando no esquecimento da principal preocupação de um oftalmologista: a prevenção da cegueira. Para que isto seja revertido, é necessário que os conhecimentos adquiridos sejam aplicados dentro de uma visão ampla, científica, socioeconômica, psicológica e humanística.

\section{FUNÇÃO ADMINISTRATIVA}

$\mathrm{Na}$ Universidade moderna, paralelamente às atividades de ensino, pesquisa e de prestação de serviço à comunidade, impõe-se, hoje, ao docente a função administrativa, a de coordenar e fornecer condições para que aquelas se desenvolvam da maneira mais fluente. Os departamentos passaram a gerar e a gerir seus próprios recursos, fundamentais para o desenvolvimento de todas as suas atividades. O docente deve contribuir para tal processo, facilitando a criação de infra-estrutura que inclua capacidade contábil, de administração de despesas e de recursos. Os últimos, insuficientes, devem provir não somente do atendimento ao SUS, uma vez que passaram a depender do atendimento a convênios, das campanhas comunitárias, de cursos oferecidos à comunidade médica e de projetos de pesquisa, realizados em parceria com a indústria farmacêutica ou patrocinados por órgãos de fomento à pesquisa. É fundamental que o docente apresente criatividade na geração de recursos, visando atingir a auto-suficiência do departamento, não só do ponto de vista de ensino e pesquisa, mas, também, do ponto de vista financeiro.

O desafio administrativo do docente passa pela elaboração de um planejamento estratégico, que crie mecanismos e motive o grupo para atingir os fundamentos básicos de uma administração eficiente: fazer 
bem feito, realizar mais e, sobretudo, fazer o novo com o mínimo de recursos.

Trata-se de uma tarefa árdua, que não pode se concentrar, como se fazia há algum tempo, nas mãos do Chefe do Departamento ou do Titular da Disciplina. No que toca à parte administrativa, são várias as funções que o docente pode exercer, desde a coordenação dos Cursos de Graduação e Pós-Graduação, de Laboratórios de Investigação Médica e dos Projetos comunitários até a participação ativa no Centro de Estudos e nos cursos e congressos organizados pela
Disciplina. Independente da tarefa administrativa absorvida, o docente deve estimular o desenvolvimento de projetos, com indicação precisa de objetivos, custo e prazo de execução. Ao seu término, deverão ser avaliados os resultados, as conquistas e erros, valorizando os responsáveis pelas primeiras e procurando justificativas para os últimos.

\section{AGRADECIMENTO}

Ao Prof. Dr. Raul Maranhão e ao Prof. Dr. Celso Antonio de Carvalho, pela orientação e sugestões.

COSTA VP. The role of the professor at the university. Medicina, Ribeirão Preto, 35: 505-508, oct./dec. 2002.

ABSTRACTS: The professorship at a University is the final product of a long and costly formative process that only ends when the professor realizes the necessity of exercising the activity of a cultural multiplier. This activity requires a level of consciousness not always acquired after an extensive scientific production. This article aims to discuss a triad, in the center of which the professor needs to position him(her)self: teaching, community work, and research. The author emphasizes the relationship between theses three components, as well as the necessity of a balanced dedication of the professor to each element of this triad.

UNITERMS: University. Teaching, Research. Community. Responsibility.

\section{REFERÊNCIA BIBLIOGRÁFICA}

1 - RIBEIRO D. A universidade necessária. Editora P\&T, São Paulo, 1969. 275 p. 